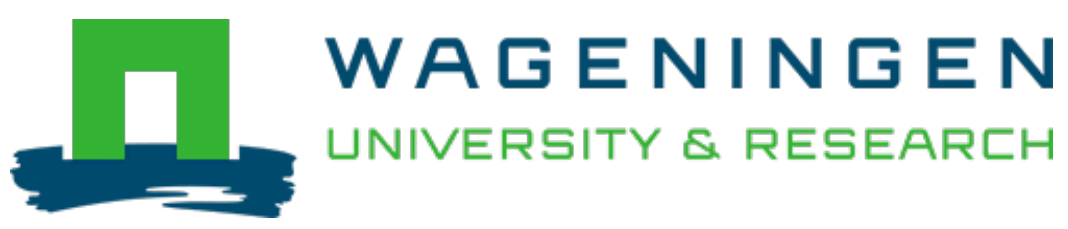

\title{
Transition towards sustainable yak farming in Bhutan : stakeholders' viewpoints and recommendations for future steps
}

International Journal of Agricultural Sustainability

Dorji, Nedup; Derks, Marjolein; Groot Koerkamp, Peter W.G.; Bokkers, Eddie A.M.

https://doi.org/10.1080/14735903.2021.1917909

This article is made publicly available in the institutional repository of Wageningen University and Research, under the terms of article $25 \mathrm{fa}$ of the Dutch Copyright Act, also known as the Amendment Taverne. This has been done with explicit consent by the author.

Article 25 fa states that the author of a short scientific work funded either wholly or partially by Dutch public funds is entitled to make that work publicly available for no consideration following a reasonable period of time after the work was first published, provided that clear reference is made to the source of the first publication of the work.

This publication is distributed under The Association of Universities in the Netherlands (VSNU) 'Article $25 \mathrm{fa}$ implementation' project. In this project research outputs of researchers employed by Dutch Universities that comply with the legal requirements of Article $25 \mathrm{fa}$ of the Dutch Copyright Act are distributed online and free of cost or other barriers in institutional repositories. Research outputs are distributed six months after their first online publication in the original published version and with proper attribution to the source of the original publication.

You are permitted to download and use the publication for personal purposes. All rights remain with the author(s) and / or copyright owner(s) of this work. Any use of the publication or parts of it other than authorised under article $25 \mathrm{fa}$ of the Dutch Copyright act is prohibited. Wageningen University \& Research and the author(s) of this publication shall not be held responsible or liable for any damages resulting from your (re)use of this publication.

For questions regarding the public availability of this article please contact openscience.library@,wur.nl 


\section{Transition towards sustainable yak farming in Bhutan: stakeholders' viewpoints and recommendations for future steps}

Nedup Dorji, Marjolein Derks, Peter W.G. Groot Koerkamp \& Eddie A.M. Bokkers

To cite this article: Nedup Dorji, Marjolein Derks, Peter W.G. Groot Koerkamp \& Eddie A.M. Bokkers (2021): Transition towards sustainable yak farming in Bhutan: stakeholders' viewpoints and recommendations for future steps, International Journal of Agricultural Sustainability, DOI: 10.1080/14735903.2021.1917909

To link to this article: https://doi.org/10.1080/14735903.2021.1917909

\section{Published online: 28 Apr 2021.}

Submit your article to this journal $\widetilde{ }$

山 Article views: 48

Q View related articles ¿

View Crossmark data $[\pi$ 


\title{
Transition towards sustainable yak farming in Bhutan: stakeholders' viewpoints and recommendations for future steps
}

\author{
Nedup Dorji (1) ${ }^{a}$, Marjolein Derks ${ }^{b}$, Peter W.G. Groot Koerkamp ${ }^{b}$ and Eddie A.M. Bokkers ${ }^{c}$ \\ ${ }^{a}$ Department of Animal Science, College of Natural Resources, Royal University of Bhutan, Lobesa, Bhutan; ${ }^{b}$ Farm Technology \\ group, Wageningen University \& Research, Wageningen, Netherlands; 'Animal Production Systems group, Wageningen \\ University \& Research, Wageningen, Netherlands
}

\begin{abstract}
The Bhutanese government initiated a highland development programme in the year 2016 to promote yak farming because the number of yak farming families is declining. However, there are several cross-cutting policies and issues that affect successful implementation of interventions to support yak farming in transition. We studied the challenges and opportunities to sustain yak farming and related trade-offs around problems and solutions through individual and focus group interviews with six stakeholder groups (i.e. herders from two regions, extensionists, park rangers, livestock officials, and forest officials). Overall the herders rated forage availability and yak mortality as the main threats to yak farming, while government officials rated labour availability as the main threats. Most problems and solutions that were identified in the focus group interviews had diverging views among the stakeholder groups. There is clearly a need for a multistakeholder dialogue aiming to discuss problems and solutions together. This should take away misleading and disputed claims, and provide understanding about the approach to cope with risks and uncertainty around transhumance yakbased communities. A strong collaboration should lead to appropriate policy, which would reduce challenges and barriers, and simultaneously give opportunities to herders and their children to stay in yak farming in future.
\end{abstract}

KEYWORDS

Transhumance; sustainability; stakeholder group; convergence/ divergence framework; policy

\section{Introduction}

Yaks (Poephagus grunniens or Bos grunniens) are the main animals in farming systems for highland pastoralists residing in Bhutan $2500 \mathrm{~m}$ above sea level. In the ten districts of Bhutan where this is the case, about 41,000 yaks were recorded in 2018 (DoL, 2018). These transhumance communities largely depend on yaks for food (meat, milk and its products), clothes, and source of income through sale of excess yak products. Castrated yak bulls are used as pack animals for transportation and traction. The transhumance yak farming system is a cyclic process and follows a vertical migration (Krishnan et al., 2016; Shirasaka et al., 2013; Tiwari et al., 2020). The yak herders with their herds migrate between summer (high altitude) and winter rangelands (low altitude) depending on forage availability and weather conditions.

In the transhumance yak farming system, forage shortage, inaccessibility to veterinary and health services, mortality and labour shortage to herd are the main constraints (Dorji et al., 2020; Wangchuk \& Wangdi, 2015; Wangdi, 2016). The current resource constraints in yak farming have further escalated due to increasing pressure from external factors, such as socioeconomic developments, policy dynamics (Dorji et al., 2020), and climate change (Wangchuk \& Wangdi, 2018). In the past, for example, when herds reached the winter rangelands, all family members were involved in yak farming, including herding, feeding supplements, processing milk to butter and cheese, and marketing of yak 
products. At present, however, most men in the central and western yak farming regions are predominately involved in off-farm activities, while women take responsibility to look after the yaks (Wangchuk \& Wangdi, 2015). In addition, most young literate pastoralists are said to be unwilling to venture into yak farming because it is a tough way of life (Dorji et al., 2020; Wangdi, 2016). They are increasingly engaged in off-farm opportunities, such as collecting of medicinal plants and mushrooms (cordyceps), or they migrate to towns, which offer better facilities (Wangchuk \& Wangdi, 2015). These activities have increased the horse population in the rangelands as these animals are used for transportation, which has led to increased feed competition and consequently degradation of rangelands. Increasing temperature in the mountains due to climate change affects the type of vegetation. It seems that more shrubs are growing in areas where previously grass was predominant (Wangchuk \& Wangdi, 2018).

The number of yak farming families is declining rapidly in Bhutan 1400 families in 1996 and 968 in 2013 (Wangdi, 2016) and also in other yak farming regions (Haynes \& Yang, 2012; Tiwari et al., 2020; Wiener et al., 2003). This decline is of socio-political and economic concern to the Bhutanese government, as the transhumance pastoralists play an essential role in environmental stewardship while preventing resource exploitation in the alpine regions (Wangdi, 2016). Although yak farming is of less interest among the youth of transhumant families, in the current five-year plan of the Bhutanese government it was stated that the government aims to promote sustainable livelihoods of yak farming families (MoAF, 2019). A similar situation where youth of transhumant families is not interested to take up yak farming is observed in other yak farming regions (Haynes \& Yang, 2012; Tiwari et al., 2020).

In the past, a handful of strategies were initiated in response to resource constraints. Artificial insemination (yak semen imported from China) was initiated in order to improve yak breed and performance. However, only a few yak herders could access artificial insemination facilities because most herds are located in very remote areas and yak cows are scattered during the breeding season (Phuntsho \& Dorji, 2016). This indicates that the solution to the constraint has not really been thought through in advance and shows that problems should be evaluated from different perspectives prior to implementation of an improvement strategy. For instance, promotion of community-based ecotourism has encouraged the local community of Ladakh, India to conserve the snow leopard (Panthera uncia), which had a poor reputation among the locals in the past, because of financial benefits (Maheshwari \& Sathyakumar, 2019; Vannelli et al., 2019). Moreover, it is very difficult to achieve desirable outcomes for different stakeholders because there are several crosscutting policies, regulations, and acts that may hinder the successful implementation of interventions. For instance, the Forest and Nature Conservation Act 1995 that prohibits burning and clearing of shrubs around rangelands seems to conflict with communities' traditional practice of rangeland management and with the pasture development programme of the livestock department. So, any future policy interventions to support yak farming should align with requirements and wishes of different stakeholders (governmental agencies, yak-based communities) as much as possible. Yak farming is in transition, but it is unclear how different stakeholders perceive the challenges and opportunities related to this transition. Therefore, this study aimed to identify the perceived challenges and opportunities to sustain yak farming and related trade-offs around problems and solutions through (individual and focus group) interviews with different stakeholders. The outcome of this study can help policy makers choose which direction they could take in order to support and maintain yak farming in the future.

\section{Methods}

\subsection{Stakeholder analysis and recruitment}

We listed eight potential stakeholder groups who are believed to have an interest in and influence on yakbased transhumant communities: yak herders, local livestock extensionists (referred hereafter as extensionists), park rangers of national parks and nature reserves, policy makers of the Department of Livestock (referred as livestock officials), policy makers of the Department of Forest and Park Services (referred as forest officials), tourism industry, NGOs (e.g. Royal Society for the Protection of Nature), and citizens in towns. Five key stakeholders were identified on the basis of Eden and Ackermann's power versus interest matrix (Bryson, 2004; Rosso et al., 2014; Schmeer, 1999) (Table 1). Tourism industry, NGOs and citizens in towns were excluded because these stakeholder groups have a relative low interest and power to influence the issues or 
Table 1. Stakeholders relationship with yak-based transhumant communities.

\begin{tabular}{|c|c|c|c|c|}
\hline Group & Relation and information they may provide & $\begin{array}{l}\text { Importance / } \\
\text { interest }\end{array}$ & $\begin{array}{l}\text { Influence / } \\
\text { power }\end{array}$ & $\begin{array}{l}\text { Role to yak } \\
\text { farming }\end{array}$ \\
\hline Yak herders & Experience on current situation on yak farming practices & High & Little & Support \\
\hline $\begin{array}{r}\text { Local livestock } \\
\text { extensionists }\end{array}$ & $\begin{array}{l}\text { Extensionist deals with herders on a regular basis (e.g. } \\
\text { train, support and provide advice to herders on } \\
\text { production and health of livestock), and implement } \\
\text { livestock policy at the grass-root level }\end{array}$ & High & Medium & Support \\
\hline $\begin{array}{l}\text { Park rangers of protected } \\
\text { areas }\end{array}$ & $\begin{array}{l}\text { Yak farming regions are located within protected areas } \\
\text { (parks and sanctuaries) and rangers often deal with yak } \\
\text { herders, and implement forest policy at the grass-root } \\
\text { level }\end{array}$ & Medium & Medium & $\begin{array}{l}\text { Support and } \\
\text { hinder/ } \\
\text { oppose }\end{array}$ \\
\hline $\begin{array}{l}\text { Policy maker: Department } \\
\text { of Livestock }\end{array}$ & $\begin{array}{l}\text { Develops policy based on recent information and priorities } \\
\text { of the organization to maintain and support yak farming }\end{array}$ & High & High & Support \\
\hline $\begin{array}{l}\text { Forest official: Department } \\
\text { of Forest and Park } \\
\text { services }\end{array}$ & $\begin{array}{l}\text { Update information on the policies and priorities of the } \\
\text { organization for conservation, protection, and } \\
\text { sustainable utilization of natural resources }\end{array}$ & Medium & High & $\begin{array}{l}\text { Support and } \\
\text { hinder/ } \\
\text { oppose }\end{array}$ \\
\hline Tourism industry & $\begin{array}{l}\text { Hire horse from yak-based communities for tourist } \\
\text { trekking, and visit yak farming village }\end{array}$ & Low & Little & $\begin{array}{l}\text { Support and } \\
\text { hinder/ } \\
\text { oppose }\end{array}$ \\
\hline NGOs & Preserve natural environment & Low & Little & Hinder/oppose \\
\hline Citizens in towns & Yak product consumers & Low & Little & Support \\
\hline
\end{tabular}

earlier identified themes (Dorji et al., 2020). The remaining stakeholder groups can be divided based on their backgrounds: yak herders and government officials (extensionists, park rangers, livestock officials, forest officials).
Two stakeholder groups of yak herders were recruited, one group $(n=10)$ in the eastern region (Merak block), and one group $(n=10)$ in the central region (Sephu block) (Figure 1). These two yak farming regions were selected based on differences

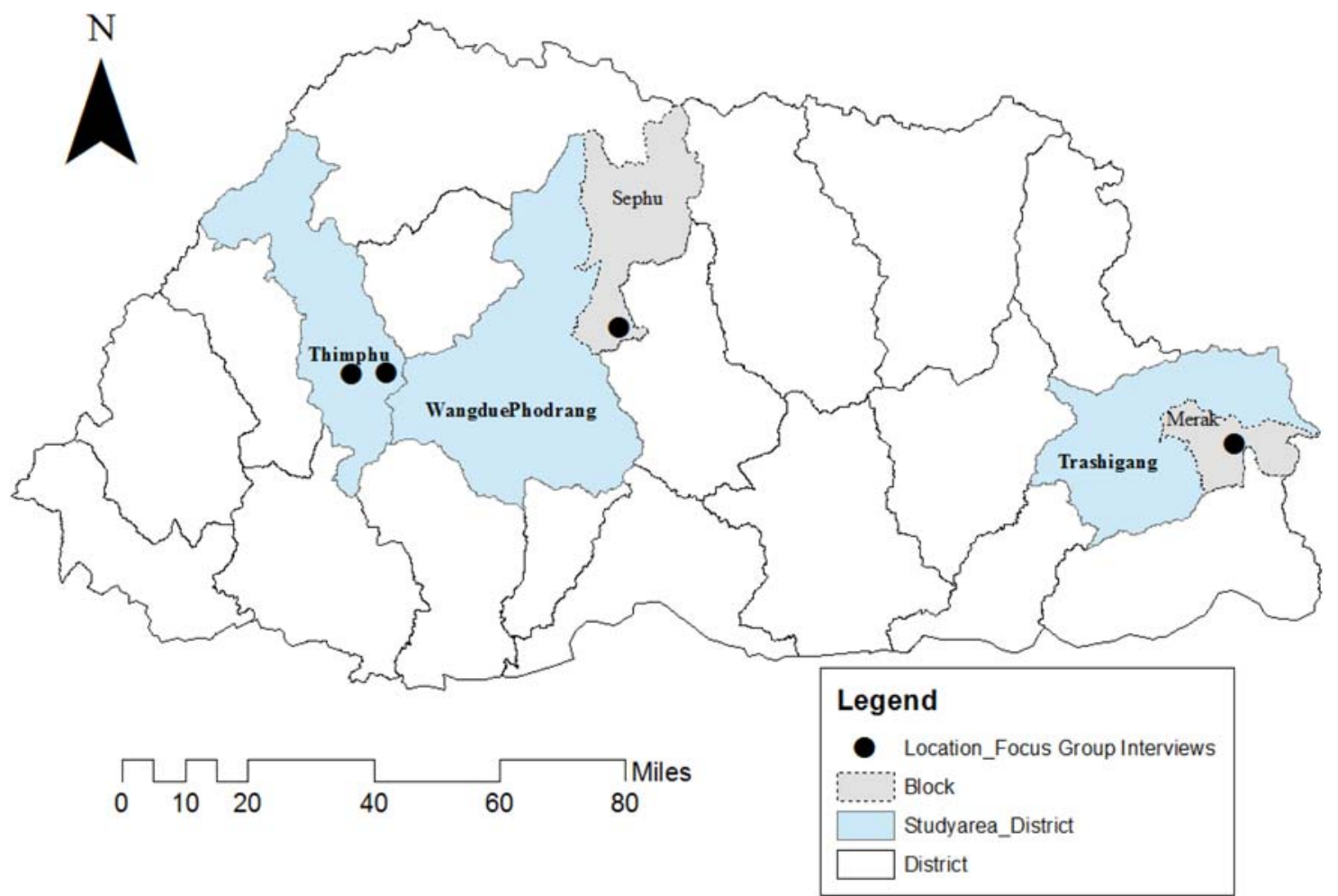

Figure 1. Map of Bhutan showing the location for conducting the Focus group interviews (indicated by the solid black circle). The Merak research area is located within Trashigang district and Sephu within WangduePhodrang district. 
in the alternate source of income for these communities (cordyceps is collected in the central region, but not in the eastern region) and on the different yak dairy products they produce (fermented cheese in the eastern region and dry cheese in the central region, Derville \& Bonnemaire, 2010; Dorji et al., 2020). Participants were recruited from the same village or nearby villages within the region. Extensionists $(n=3)$ and park rangers $(n=4)$ were recruited based on information from a previous field study in 2017. During the time of visit in the central yak farming region, four park rangers of Wangchuck Centennial Parks in the central Bhutan were available. However, park rangers of Sakteng Wildlife Sanctuary were not interviewed because they were not available during the time of visit even though they were informed about the visit (all rangers were engaged in patrolling within the park). Recruitment of extensionists was challenging because yak farming blocks are distantly located from one another. We contacted extensionists who were working $(n=1)$ or worked $(n=2)$ in yak-based communities in the eastern region to take part in the study. Extensionists of the central region were not recruited because these yak farming blocks were up to three day walking from the visited yak farming block (Sephu). Livestock officials $(n=6)$ were recruited from the Department of Livestock, Ministry of Agriculture and Forests (MoAF) in consultation with the Director General of the department. Forest officials $(n=4)$ were recruited from the Department of Forest and Park Services (DoFPS), MoAF based on their expertise and availability. Individual participants were contacted and invited to take part in the focus group meetings. In total 37 participants took part in the different focus group meetings. Meetings were organized with participants of one stakeholder group to enable them to freely share their opinions and views (Krueger, 2002; Ochieng et al., 2018).

Before data collection started, a verbal consent was obtained from the participants that they agreed to take part in the study and for audio-recording of the interviews. Participants were also assured that their identity would remain confidential. Both individual interviews and focus group interviews were conducted on the same day.

\subsection{Individual interviews}

Prior to the focus group interview (FGI), herders were interviewed face-to-face because most were illiterate, while the government officials were asked to fill out a question list themselves. Both were conducted to gather information about their opinion, perception and knowledge about yak farming. The following topics were addressed:

- Participants' perceived level of familiarity with four main themes related to yak farming in Bhutan identified from the previous study (Dorji et al., 2020): the market situation to sell yak products, labour availability to herd yaks, yak mortality, and forage availability on rangelands. A 4-point Likert-scale was used: 1 , not at all aware; 2 , to a small extent aware; 3 , to a moderate extent aware; 4, to a large extent aware. This question was not asked to yak herders.

- Participants had to rank the three most important threats to sustaining yak farming from the four themes and the reasons why they rank it like this (open-ended question).

- Participants' opinion on trends on the number of farming families over the years. A 5-point Likert item was used: 1 , definitely decrease; 2 , probably decrease; 3, remain the same; 4, probably increase; 5 , definitely increase.

\subsection{Focus group interviews}

Perceptions of the different key stakeholders in yak farming practices were used to identify challenges and opportunities for implementation of interventions to sustain yak farming. From November to December 2019, six FGls were conducted, one for each stakeholder group and with 3-10 participants per FGI. FGls were organized close to where participants were working. The facilitator gave an informal introduction to the participants and let the group agree on the house rules during the meeting (Krueger, 2002; Ochieng et al., 2018). The facilitator briefed the participants on the aims and expectations for the FGI. All FGls were facilitated by the first author and a research assistant took notes on the contents of discussion and organized the audio-recordings. Since we were depending on availability and voluntarily willingness to participate in $\mathrm{FGl}$, the desired number of six participants per group was not completely met (Krueger \& Casey, 2000).

In the FGl, the four themes around yak farming in Bhutan were used as input and served as basis for the discussion. The FGI was conducted using a list of predefined questions prepared by the research team, and 
a probing technique (e.g. what, which) was used to specific individuals, whenever required. The procedure for the FGI was: firstly, individual participants gave their opinion on the current situation with respect to each theme (forage availability, market situation, yak mortality, labour availability and rural-urban migration); secondly, the group listed potential factors that affected each theme as indicated above; and finally from a list of factors (provided by the facilitator to ensure the same list of factors in all FGls) the group had to discuss and assign the first three most important factors (one shared group opinion), to give reasons why they ranked it like this, and to suggest solutions in what way these issues (factors) can be dealt with. The facilitator actively intervened to stimulate quiet and shy individuals participating in the FGls to also speak up during the process of reaching consensus.

A FGl lasted on average 110 min ranging from $80 \mathrm{~min}$ (forest officials) to $150 \mathrm{~min}$ (livestock officials). FGls were both conducted in English and the Bhutanese national language (Dzongkha) for extensionists, park rangers, livestock officials and forest officials. The Bhutanese national language for the herders of the central region and local dialect (sharchopkha) for the herders of the eastern region was used to conduct the FGls. The protocol and questions for the FGls were tested with three Bachelor of Science students studying Animal Science at the College of Natural Resources, Royal University of Bhutan.

\subsection{Data processing}

Individual interviews and FGls were analysed using the constant comparison analysis (Onwuegbuzie et al., 2009). For the threats to yak farming, $3=$ first; $2=$ second; and $1=$ third most important threats to yak farming were assigned. The values assigned by individual participants on each threat were summed per group, and the total score was divided by a total number of participants in a group to correct for the differences in sample size to obtain the threat score. The threat score of each theme indicates the perceived level of threat to yak farming, with a higher threat score indicating a greater threat to yak farming. Other data were analysed descriptively.

\section{Results}

\subsection{Characteristics of respondents}

Herders of the eastern region $(n=10)$ were mainly illiterate $(n=8)$ and 3 were female. Their median age and herding experience was 42 and 17.5 years (range 9-50 years). Herders of the central region ( $n$ $=10)$ were also mostly illiterate $(n=8)$ and female $(n=7)$. Their median age and herding experience was 40 and 25 years (range 15-30 years). All extensionists $(n=3)$ were male with a diploma (2-years programme) in animal husbandry, and a median age and working experience were 31 and 3 years (range 3-7 years). All park rangers $(n=4)$ were male with a one-year certificate $(n=2)$, diploma ( $n$ $=1$ ) and bachelor's degree $(n=1)$ in forestry, and a median age and working experience was 33 and 3.5 years (range 2-8 years). Five of six livestock officials were male with education level ranging from a diploma in animal husbandry to a $\mathrm{PhD}$ in epidemiology. Their median age and working experience was 44.5 years and 5 years (range 2-25 years). Likewise, three out of four forest officials were male with education level ranging from a bachelor's degree in forestry to a PhD in sustainable forest management. Their median age and working experience was 33 and 3.5 years (range 3-30 years).

\subsection{Individual opinions}

\subsubsection{Level of familiarity with yak farming issues}

Most government officials stated that they were familiar with the mortality, forage, labour and market situation in relation to yak farming (Figure 2). Three forest officials mentioned that they were aware of the current situation of yak-based communities from different sources, including media, government website and blogs, and during meetings and seminars.

\subsubsection{Trends on the number of yak farming families}

All participants of four stakeholder groups (central herders, extensionists, park rangers, livestock officials) mentioned that the number of yak farming families has decreased over the last 10 years, while a few participants (eastern herders, forest officials) were unsure about the past trends or said the number of families had increased (eastern herders) (Figure 3). All participants of three stakeholder groups (central herders, extensionists, park rangers) expected that the number of yak farming families will further decline in the next 10 years (Figure 3 ). The reasons stated by participants were that most young pastoralists are not interested in yak farming because of an alternative source of income. Nonetheless, the eastern herders thought that the yak farming 

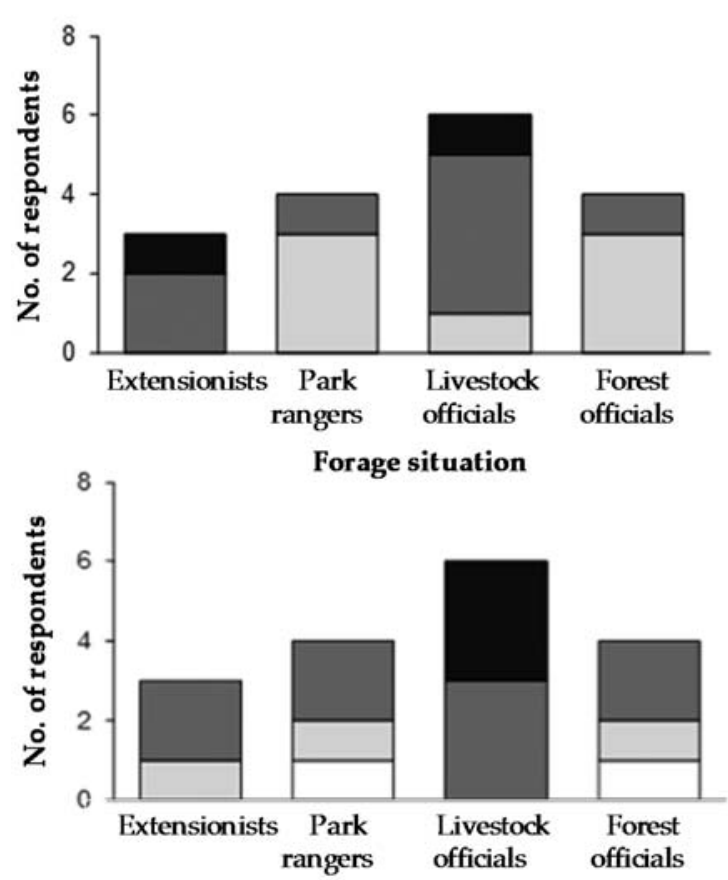

Labour situation
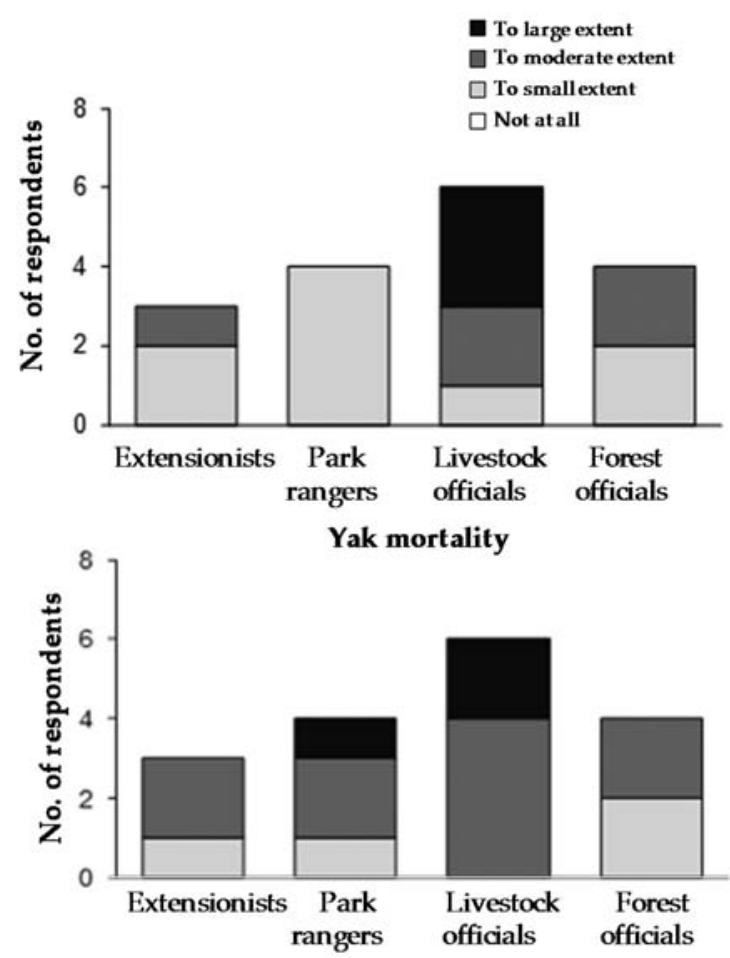

Market situation

Figure 2. Number of participants per FGI and their level of familiarity on the themes related to yak farming.

families would increase or stay the same due to remoteness of these yak farming blocks from western towns and job employment.

\subsubsection{Threats to yak farming}

Herders from the central and eastern region perceived forage availability on rangelands as a principal threat. Herders of the central region also rated yak mortality as a principal threat to yak farming (Table 2). In contrast, government officials considered labour availability (park rangers, livestock officials, forest officials) and rural-urban migration (extensionists, park rangers) as the main threats to yak farming. Livestock officials also perceived forage availability as an important threat to yak farming. We decided to consider the first most important threat to yak farming
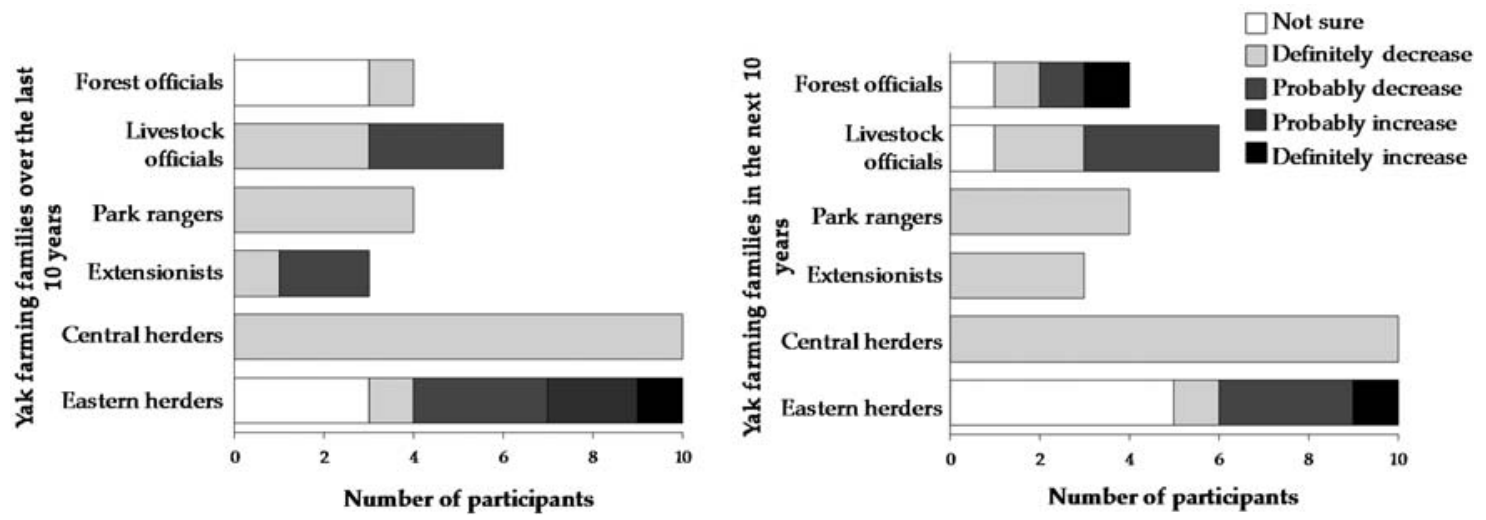

Figure 3. Participants' opinion on the trends of the number of yak farming families over the years. 
Table 2. Average of the participant's score on the threats to sustain yak farming.

\begin{tabular}{lccccc}
\hline Group & Forage availability & Yak mortality & Labour availability & Rural-urban migration & Market situation \\
\hline Eastern herders & $\mathbf{2 . 7}$ & 1.7 & 0.2 & 0.4 & 0.6 \\
Central herders & $\mathbf{1 . 9}$ & $\mathbf{1 . 9}$ & 1.5 & $\mathbf{2 . 7}$ & 0 \\
Extensionists & 1.3 & 0 & 2.0 & $\mathbf{2 . 0}$ & 0 \\
Park rangers & 0 & 0.7 & $\mathbf{2 . 3}$ & 1.5 & 0 \\
Livestock officails & $\mathbf{1 . 8}$ & 0.8 & $\mathbf{1 . 7}$ & 1.5 & 0.2 \\
Forest officials & 1.5 & 0.8 & $\mathbf{2 . 5}$ & 0.5
\end{tabular}

Notes: Higher numbers indicate higher threats to yak farming (in bold is the most important threat(s) to yak farming per focus group).

as perceived by different stakeholder groups, and the second most important threat when the value was approximately equal to the first threat $(\geq 0.6$ rounded up to 1) for the most important threats.

Participants (eastern herders and livestock official) who rated forage availability as the main threat mentioned that rangeland division among family members, increased livestock population, and climate change as reasons for this (Table 3 ). With regard to labour availability and rural-urban migration, access to education for children, modernization and alternative sources of income were mentioned as reasons for these threats (Table 3). Overall, most participants considered the market situation to sell yak products as the least threat to yak farming.

\subsection{Group opinions}

The findings are presented in three subsections: (i) current situation and the factors affecting a theme; (ii) solutions to the most important issues; and (iii) convergence/divergence views on problems and solutions.

\subsubsection{Current situation}

\subsubsection{Forage availability}

Herders from both regions expressed that they experience less forage available in rangelands, which they think has decreased over the years. Except the park rangers, all stakeholder groups supported this. The argument given by park rangers was that the herders constantly migrate with their herd from one rangeland to another in search for forage, which is an adaptive strategy. Nonetheless, park rangers also acknowledge various factors that affect forage availability on rangelands (Figure 4). This possibly explains why the park rangers do not recognize low forage yields in rangelands as they are not trained in pasture growth and management.

The traditional practice of dividing rangeland among family members affects forage availability according to eastern herders, extensionists, and livestock officials. Three stakeholder groups ranked the increased cattle and cattle-yak hybrids as the most important factor affecting the forage availability on rangelands. Some stakeholder groups also thought that increased horse population is a cause of forage shortage.

Three stakeholder groups (eastern herders, livestock officials, forest officials) criticized the Forest and Nature Conservation Act 1995 of Bhutan (used as the Forest Act 1995) for causing shrub to proliferate on rangelands which in turn has led to forage shortage. Forest officials emphasized the significant impact of climate change (less precipitation) on forage production on the rangeland.

\subsubsection{Yak mortality}

Herders mentioned that they experience yak mortality, which was also recognized by other stakeholder groups. All stakeholder groups mentioned that endangered wild predators, such as snow leopard and Asiatic wild dog (Cuon alpinus) were the

Table 3. Participants' reasons for ranking the first three most important threats to yak farming.

\begin{tabular}{ll}
\hline Aspect & \multicolumn{1}{c}{ Reasons (source, $n$ ) } \\
\hline $\begin{array}{l}\text { Forage } \\
\text { availability }\end{array}$ & Increased cattle, cattle-yak hybrids, and yak \\
& population (EH, 1; CH, 4; EA, 1; LO, 3; FO, 1) \\
& Rangeland division among family members (EH, \\
& $9 ;$ LO, 1) \\
& Climate change (FO, 2) \\
& Shrub proliferation in rangelands (EA, 1) \\
& Competition with wild herbivores (FO, 2) \\
Yak mortality & Wild predation on yaks (EH, 1; CH, 10; PR, 2; LO, \\
& 2; FO, 1) \\
& Disease outbreak (EH, 1; LO, 2; FO, 1) \\
& Plant poisoning (EH, 6) \\
Labour & Alternative source of income (EH, 2; CH, 8; EA, 1; \\
availability & PR, 3; LO, 3; FO, 2) \\
& Access to modern education (CH, 2, EA, 1: LO, 1; \\
Rural-urban & FO, 1) \\
migration & Alternative source of income and easy lifestyle \\
& in towns (EH, 4; CH, 3; EA, 2; PR, 2; LO, 2; FO, 3)
\end{tabular}

EH: eastern herders; $\mathrm{CH}$ : central herders; EA: extensionists; PR: park rangers; LO: livestock officials; FO: forest officials. 


\section{Group list potential factors}

Eastern herders: increased yak, cattle and cattle-yak hybrids population, rangeland division, Forest and Natural Conservation Act 1995

Central herders: increased yak, cattle and cattle-yak hybrids, and horse population

Extensionists: increased wild herbivores, increased yak, and cattle and cattle-yak hybrids, horse population, rangeland division, shrub proliferation, soil erosion/landslide

Park rangers: increased wild herbivores increased with yak, cattle and cattle-yak hybrids, and horse population

Livestock officials: increased wild herbivores, increased cattle and cattle-yak hybrids, Forest and Natural Conservation Act 1995, Land Act 2007, soil erosion/landslide, less precipitation, global warming

Forest officials: increased yak, cattle and cattle-yak hybrids, and horse population, Forest and Natural Conservation Act of 1995, less precipitation, global warming, no forage storage practices

Additional potential factors

Cordyceps collection site

\section{One shared group opinion on the most important factors}

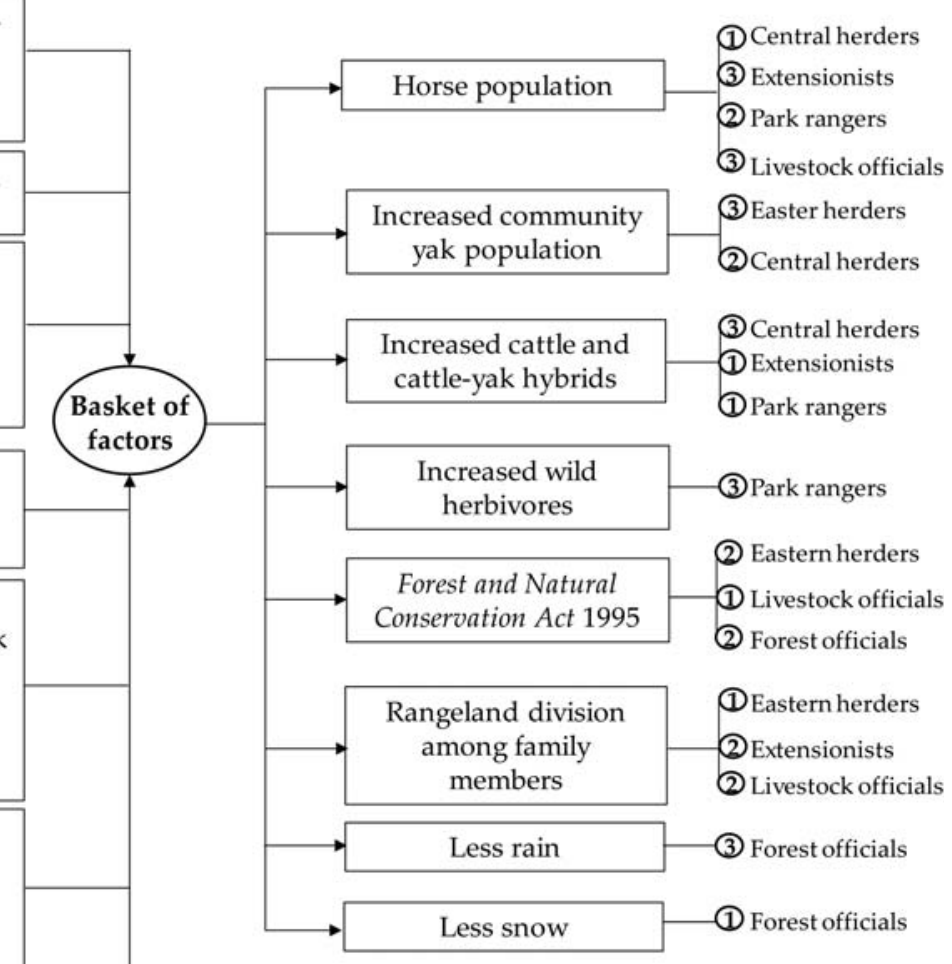

(1) First rank (2) Second rank (3) Third rank

Figure 4. Process involved during group consensus ranking the first three most important factors affecting forage availability on rangelands. Participants listed factors (left side) and facilitator provided potential factors (bottom-left side) to form a basket of factors (central). From the basket of factors the different stakeholder groups ranked the first three most important factors (right side).

leading cause of yak mortality. In fact, all stakeholder groups expressed that the loss of yaks to wild predators has continued to increase over the years. In addition, one forest official and two livestock officials viewed that the number of stray dogs in yak farming has increased, and these dogs attack young animals during food scarcity. Contamination by other animals and drying up of water sources was seen as another important cause to yak morality. Other mentioned causes of yak mortality were forage shortage, intake of poisonous plants, accident of yaks and bad weather conditions (Figure 5).

\subsubsection{Labour availability and rural-urban migration}

Herders think that the available family labour is sufficient to contribute to yak farming. In contrast, all government officials believed that yak farming families experienced labour shortage due to socioeconomic developments (e.g. access to education for children, better facilities offered in towns). All stakeholder groups acknowledged that socioeconomic developments triggered young pastoralists to migrate to towns and consequently caused labour shortage (Figure 6). In yak farming villages the schools are at primary-level and most children leave their village to pursue higher education in other regions. Besides impact of access to education, four stakeholder groups (central herders, park rangers, livestock officials, forest officials) stated the hardship in yak farming combined with lucrative alternative sources of income greatly affected both young and adult pastoralists' interest in yak farming. Consequently, the number of successors to take up yak farming was said to decline over the years (all stakeholder groups). 


\begin{tabular}{l}
$\begin{array}{l}\text { Eastern herders: wild predators, } \\
\text { forage shortage, intake of poisonous } \\
\text { plant and poisonous water }\end{array}$ \\
$\begin{array}{l}\text { Central herders: wild predators, forage } \\
\text { shortage, disease outbreak, accidents } \\
\text { with yaks }\end{array}$ \\
\hline $\begin{array}{l}\text { Extensionists: wild predators, forage } \\
\text { shortage, intake of poisonous plant, } \\
\text { disease outbreaks, accidents with yaks, } \\
\text { bad weather conditions }\end{array}$
\end{tabular}

Park rangers: wild predators, forage shortage (winter), disease outbreak

Livestock officials: wild predators, stray dogs, forage shortage, intake of poisonous plant and poisonous water, disease and gid infestation, bad weather conditions

Forest officials: wild predators, forage
shortage, disease and gid infestation,
bad weather conditions

Additional potential factors

Unavailability of vet. services, no or poor shed quality, water shortage

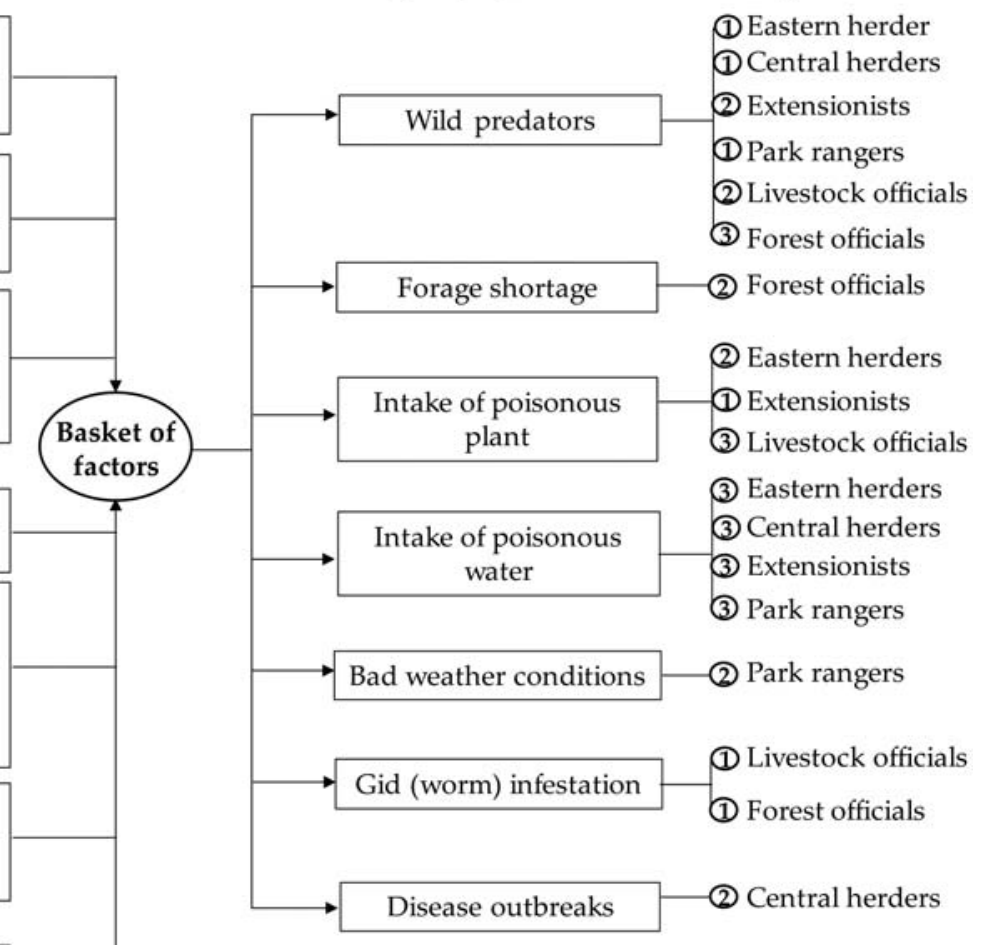

(1) First rank (2) Second rank (3) Third rank

Figure 5. Process involved during group consensus ranking the first three most important causes of yak mortality. Participants listed factors (left side) and the facilitator provided potential factors (bottom-left side) to form a basket of factors (central). From the basket of factors the different stakeholder groups ranked the first three most important factors (right side).

\subsubsection{Market situation}

Herders mentioned that they were able to sell their yak products, which was also supported by the extensionists and park rangers, although all see some limitations. Four livestock officials and one forest official believed however that herders would experience problems in selling yak products. Factors that were mentioned to affect sales of yak products were: distance to reach urban market, poor or no road infrastructure, no outlet to sell yak products, and competition with cheap imported dairy products such as margarine from India (Figure 7).

According to most stakeholder groups, a combination of poor infrastructure and long distances to reach markets were the main factors that limit the sale of yak products because most yak farming regions are not connected with motorable roads. This has mainly an effect on the sale of yak butter because that product has a low shelf-life. Poor hygiene in processing yak products and competition with cheap imported dairy products and dairy development in the lowlands were also considered to negatively affect the sales of yak products. Furthermore, the eastern herders rated the increased consumer awareness of the health effects of blood pressure due to intake of butter as a threat to the sales of yak butter. Another reason was that yak products are considered the same as the products their ancestors produced, though more expensive than the butter from dairy cow and imported dairy products (livestock officials, forest officials).

\subsubsection{Solutions to the most important issues}

\subsubsection{Solutions proposed to forage shortage}

The basket of solutions for the most important issues suggested by stakeholder groups is presented in Table 4. Stakeholder groups suggested to improve pasture to alleviate forage shortage. In winter 
Group list potential factors

Eastern herders: access to modern education, rural-urban migration

Central herders: access to modern education, alternative source of income, family planning

Extensionists: access to modern education, rural-urban migration

Park rangers: access to modern education, rural-urban migration, alternate source of income

Livestock officials: access to modern education, rural-urban migration, alternative source of income

Forest officials: access to modern education, rural-urban migration, alternate source of income

\section{Additional potential factors}

Diversification of livestock farming

.

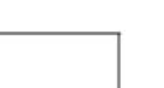

(n)
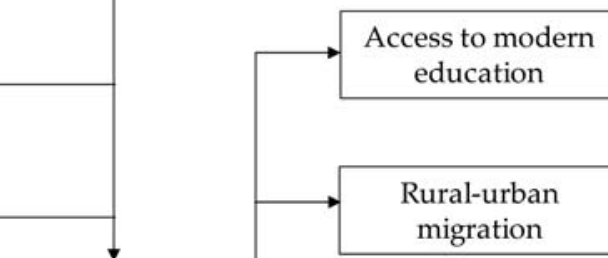

(1) All six groups

(2) Eastern herders

(2) Extensionists

(1) Park rangers

(1) Livestock officials

(2) Forest officials

Basket of factors
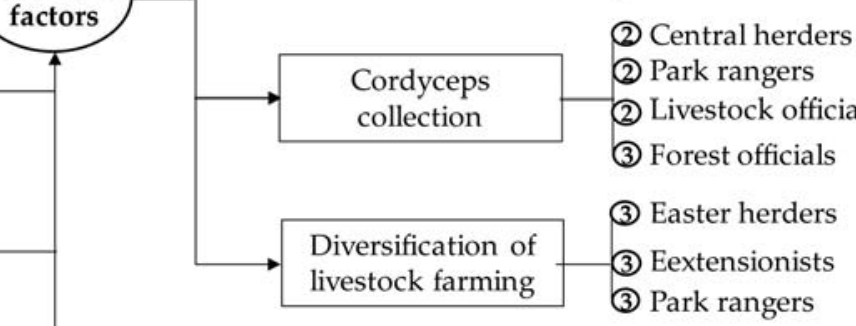

(1) First rank (2) Second rank (3) Third rank

Figure 6. Process involved during group consensus ranking the first three most important factors affecting labour availability. Participants listed factors (left side) and the facilitator provided potential factors (bottom-left side) to form a basket of factors (central). From the basket of factors the different stakeholder groups ranked the first three most important factors (right side).

rangelands where yaks graze, many unproductive local cattle walk around that are said to be owned by families not owning yaks. These cattle could be replaced by a lower number but productive cattle breeds (central herders, extensionists, park rangers, livestock officials), which will put less pressure on forage use by cattle.

There is clear evidence of conflicting opinions between and within the stakeholder groups on revising the Forest Act 1995. Herders of the eastern region and livestock officials expressed that this act should be revised. Livestock officials proposed to negotiate with other stakeholders, for example the DoFPS, to increase the rangeland areas with the argument that livelihood of communities may be more important than conservation of nature. A few participants, however, also suspected that revising the Forest Act 1995 may lead to misuse of the natural resources (livestock officials, eastern herders). Furthermore, allowing the clearing of shrubs around the rangelands could increase soil erosion (extensionists) and affect mountain ecosystems, including downstream water sources (park rangers).

\subsubsection{Solutions proposed to yak mortality}

Strategies proposed by stakeholder groups to mitigate predation on yaks were to corral weak and young animals and engage herders more in herding, keep a guard dog with the yak herd, and interventions by the government (Table 5 ).

With regard to controlling parasite and disease outbreaks preventive measures were mentioned as the most effective strategy by livestock officials and forest officials. They stated that an awareness programme and regular deworming of animals would be effective in combating worm infestations and disease outbreaks. A straightforward strategy to water poisoning was to guard yaks by not allowing them to drink dirty water and drain out stagnant water (Table 5). 


\begin{tabular}{|l|}
\hline $\begin{array}{l}\text { Eastern herders: no product } \\
\text { diversification, health concern }\end{array}$ \\
\hline $\begin{array}{l}\text { Central herders: distance travel } \\
\text { to reach urban market, product } \\
\text { hygiene }\end{array}$ \\
\hline \hline $\begin{array}{l}\text { Extensionists: product hygiene, } \\
\text { packaging, road infrastructure }\end{array}$ \\
\hline $\begin{array}{l}\text { Park rangers: product hygiene, } \\
\text { volume of product }\end{array}$ \\
\hline
\end{tabular}

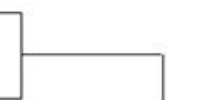

\section{Livestock officials: market to sell yak product, product hygiene, health concern}

Forest officials: poor shelf-life, road infrastructure, distance travel to reach urban market, competition with commercial cheap dairy products

Additional potential factors Dairy development in lowland, tourists (national, international)

One shared group opinion on the mostimportant factors 
Table 4. Proposed solutions for the three most important factors affecting forage availability in rangelands by the different stakeholder groups.

\begin{tabular}{ll}
\hline Factor & \multicolumn{1}{c}{ Solution (source) } \\
\hline $\begin{array}{l}\text { Increased livestock } \\
\text { population }\end{array}$ & $\begin{array}{c}\text { Develop improved pasture (all } \\
\text { stakeholder groups) } \\
\text { Keep improved cattle breed by non- } \\
\text { yak farming families (CH, EA, PR, LO, } \\
\text { FO) } \\
\text { Limit horse population when road is } \\
\text { connected (LO) } \\
\text { Awareness programme, e.g. not } \\
\text { allowing animals to stray (CH, EA, LO) } \\
\text { Allow to clear twigs and branches of } \\
\text { Forest Act 1995 } \\
\text { shrubs on rangelands (EH) and burn } \\
\text { shrubs (LO) } \\
\text { Rangeland division among } \\
\text { Develop improved pasture (EH, LO, FO) } \\
\text { Redistribute rangeland to herders } \\
\text { (LO) } \\
\text { Less precipitation }\end{array} \quad$ Combined use of rangeland (EH, EA) \\
\hline
\end{tabular}

EH: eastern herders; $\mathrm{CH}$ : central herders; $\mathrm{EA}$ : extensionists; PR: park rangers; LO: livestock officials; FO: forest officials.

limited sale of yak products (hereafter referred as problems) were diverging among stakeholder groups (Table 8). Differences in opinions between the two herder groups may be attributed to differences in tradition practices of yak farming, alternate source of

Table 5. Proposed solutions for the three most important factors causing yak mortality by the different stakeholder groups.

\begin{tabular}{ll}
\hline Factor & \multicolumn{1}{c}{ Solution (source) } \\
\hline Wild predator and stray dog & Corral weak and young yaks (EA, \\
& PR, FO) \\
& Spend more time on herding \\
& (EA, PR, FO) \\
& Keep guard dog (PR) \\
Install solar lighting system to & keep nocturnal predators away \\
& (FO) \\
& Government interventions (EH, \\
& CH, LO) \\
& Awareness not to hunt wild prey \\
& (CH) \\
& Area solution to forage shortage \\
& (LO) \\
Gid (Coenurus multiceps & Promote preventive measures, e.g. \\
multiceps) infestation and & reduce stray dogs (LO, FO) \\
disease outbreaks & Make veterinary services \\
& available (CH, EA, PR) \\
Forage shortage and plant & Train local health workers (CH) \\
poisoning & Revise the Forest Act 1995 (EH, LO) \\
& Develop improve pasture (EA) \\
Water poisoning & Research on plant poisoning \\
Cold and bad weather & (EH) \\
condition & Guard the yaks (EH, CH, EA, PR) \\
& Drain out dirty water (EH, EA, PR) \\
& Practice hay making (FO) \\
& \\
\hline
\end{tabular}

EH: eastern herders; $\mathrm{CH}$ : central herders; $\mathrm{EA}$ : extensionists; PR: park rangers; LO: livestock officials; FO: forest officials.
Table 6. Proposed solutions for the three most important factors affecting labour availability and rural-urban migration by the different stakeholder groups.

\begin{tabular}{|c|c|}
\hline Factor & Solution (source) \\
\hline $\begin{array}{l}\text { Access to modern } \\
\text { education }\end{array}$ & $\begin{array}{l}\text { Policy to support yak farming (CH, LO, FO) } \\
\text { Encourage young pastoralists in yak } \\
\text { farming (EH, EA, FO) } \\
\text { Incorporate subject related to yak } \\
\text { farming (EA, LO) } \\
\text { Upgrade the existing schools (CH) }\end{array}$ \\
\hline Rural-urban migration & $\begin{array}{l}\text { Provide basic facilities, such as } \\
\text { communication services (EA, PR, FO) } \\
\text { Awareness programme on importance of } \\
\text { yak farming and its opportunities (PR, } \\
\text { LO) } \\
\text { Provide subsidy to yak herders (FO) }\end{array}$ \\
\hline Cordyceps collection & $\begin{array}{l}\text { Establish a quota system for the amount to } \\
\text { collect (FO) }\end{array}$ \\
\hline $\begin{array}{l}\text { Livestock farming } \\
\text { diversification }\end{array}$ & $\begin{array}{l}\text { Keep less but more productive cattle } \\
\text { breeds by farming families (EA, PR) }\end{array}$ \\
\hline
\end{tabular}

EH: eastern herders; $\mathrm{CH}$ : central herders; EA: extensionists; PR: park rangers; LO: livestock officials; FO: forest officials.

income, and the location of yak farming villages. For example, the traditional method of rangeland division among family members is a cause for forage shortage in the eastern yak farming region, but not in the central region. The converging views among the stakeholder groups were, for example, access to modern education for children and rural-urban migration as the cause for labour shortage (Table 8).

\subsection{Convergence/divergence views on problems and solutions}

The mission-oriented innovation policy framework of convergence/divergence (Wanzenböck et al., 2019) was used to assess whether the views on problems and solutions converged or diverged among

Table 7. Proposed solutions for the three most important factors affecting sale of yak products by the different stakeholder groups.

\begin{tabular}{lc}
\hline Factor & Solution (source) \\
\hline $\begin{array}{l}\text { Market to sell product and dairy } \\
\text { development in lowlands }\end{array}$ & Maintain good hygiene \\
& (PR, LO) \\
Diversify yak products (LO, & FO) \\
Improve packaging of yak \\
products (FO) \\
Establish a co-operative \\
(EH, FO) \\
Road infrastructure and travel distance & Use cable crane system \\
to reach urban markets & (FO) \\
& Improve packaging of yak \\
& products (EA)
\end{tabular}

EH: eastern herders; $\mathrm{CH}$ : central herders; EA: extensionists; PR: park rangers; LO: livestock officials; FO: forest officials. 
Table 8. Classification of the problems to diverging and converging views among stakeholder groups.

\begin{tabular}{|c|c|c|}
\hline Theme & Diverging views on the problem & Converging views on the problem \\
\hline $\begin{array}{l}\text { Forage } \\
\text { availability }\end{array}$ & $\begin{array}{l}\text { Forest Act } 1995 \\
\text { Land Act } 2007 \\
\text { Rangeland division } \\
\text { Horse population } \\
\text { Increased number of yak communities } \\
\text { Increased wild herbivore population } \\
\text { Cordyceps collection sites } \\
\text { Less precipitation } \\
\text { Soil erosion }\end{array}$ & $\begin{array}{l}\text { Increased cattle and cattle-yak hybrid } \\
\text { population }\end{array}$ \\
\hline Yak mortality & $\begin{array}{l}\text { Unavailability of veterinary care services } \\
\text { Intake of poisonous plants } \\
\text { Water shortage } \\
\text { Bad and harsh weather } \\
\text { No or poor shed quality } \\
\text { Accidents with yaks }\end{array}$ & $\begin{array}{l}\text { Predation on yaks } \\
\text { Intake of contaminated water } \\
\text { Disease outbreaks } \\
\text { Forage shortage }\end{array}$ \\
\hline $\begin{array}{l}\text { Labour } \\
\text { availability }\end{array}$ & $\begin{array}{l}\text { Increase size of family yak herd } \\
\text { Alternative sources of income (tourism, cordyceps collection, diversification } \\
\text { of livestock farming) }\end{array}$ & $\begin{array}{l}\text { Access to education } \\
\text { Youth rural-urban migration }\end{array}$ \\
\hline Market situation & $\begin{array}{l}\text { Market to sell yak products } \\
\text { Road infrastructure } \\
\text { Distance travel to reach urban market } \\
\text { Tourists }\end{array}$ & Dairy development in lowlands \\
\hline
\end{tabular}

stakeholder groups in order to explore opportunities to promote yak farming. The problems and the solutions for each theme related to yak farming are categorized (Figure 8) and are placed in four quadrants depending on converging/diverging views among stakeholder groups (Wanzenböck et al., 2019). The four quadrants are: (i) disorientation: diverging views on a problem and proposed solutions among stakeholder groups, for example, effect of enactment of the Forest Act 1995 on forage availability and impact of alternative sources of income on labour availability; (ii) problem in search of a solution: stakeholder groups have converging views on the problem, but there are several vague and/or disputed solutions to approach the problem (e.g. all stakeholder groups identified that predators are the main cause for yak mortality, but lacked a clear strategy on how to deal with it); (iii) solution in search of a problem: although stakeholder groups have diverging views on the problems, they have a clear and feasible solution (e.g. the herders said that the increased yak population in a community causes forage shortage while the government officials did not think this is a cause for forage shortage. All stakeholder groups proposed to develop improved pasture); and (iv) alignment: stakeholder groups acknowledge the problems and have a clear view on the solution. The negative effect of the increased cattle population on forage availability was broadly supported by all stakeholder groups, and their solution to develop improved pasture also converged.

\section{Discussion}

We studied the challenges and opportunities to sustainable yak farming and the trade-offs around problems and solutions as experienced by different stakeholders. The individual interviews and $\mathrm{FGls}$ revealed that socioeconomic developments and strong nature conservation policies have an impact on yak-based communities. The convergence/divergence policy framework further provided new insights in and captured perceptions of different stakeholder groups on yak farming practices. A few problems and solutions had converging views among different stakeholder groups, but in most cases they were diverging.

Contestation among different stakeholder groups on problems and solutions may hamper sustainable future development. With respect to the existing Forest Act 1995, for example, the herders would like to have it changed while the governmental institutions do not support a revision because nature conservation is one of the highest priorities for the governmental institutions. The diverging views on such problems and/or solutions among stakeholder groups exist probably due to differences in knowledge levels, personalities and interests, but also due to conflicting goals and values among organizations and among farmers (Gyan \& Ampomah, 2016; Moura \& Teixeira, 2010; Wanzenböck et al., 2019). For example, contestation among different stakeholder groups regarding the commercial collection of high-altitude medical plants in Nepal 

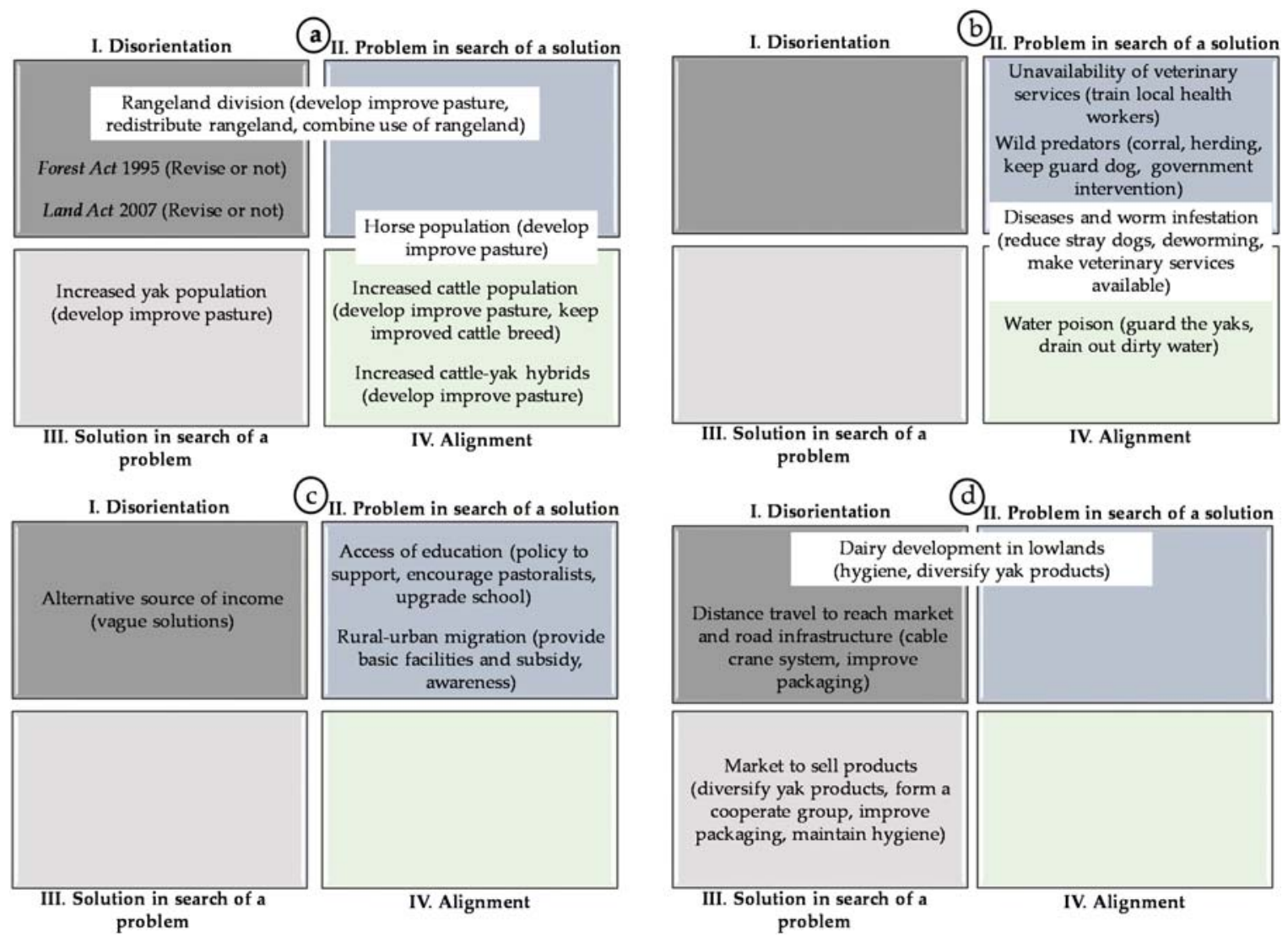

Figure 8. A two-dimensional problem-solution classification of items of each theme (solutions are given between brackets). a, forage availability in rangelands; b, yak mortality; c, labour availability; $d$, Market situation. Some problems and solutions are placed between the two quadrants because of, for instance increased horse population (central region) and horse trespassing although horse population has decreased (eastern region) caused forage shortage. Similarly, the dairy development in lowlands affects the sales of yak butter, but not of hard dry cheese.

exists (Larsen \& Smith, 2004). Thus, potential barriers and deadlocks are evident to problems and solutions with diverging views. In parallel, the diverging views on problems and solutions among stakeholder groups will also open a 'window of opportunity' for niche innovations through multi-stakeholder dialogue. This, however, can only work when there is an appropriate platform for deliberation and collective acknowledgment and definition of problems whereby stakeholder groups work together to find ways to generate solutions for the problems (Loorbach, 2010; Vogel et al., 2020; Wanzenböck et al., 2019).

\subsection{Converging views on problems and solutions}

When a problem is clearly framed with a high degree of consensus and the solutions to that problem also converge (Wanzenböck et al., 2019), there is a higher chance of success when the solution is applied in practice. In this context, the strategy proposed by the stakeholder groups to work on developing improved pasture areas to reduce forage shortages is promising as both herders and the governmental institutions support it. A similar strategy was applied in 1985 but failed (Phuntsho \& Dorji, 2016). Three crucial factors may explain this failure and should be taken into account when this strategy is tried again: (i) the policies are not always clear-cut and contradict each other at points. For example, the Forest Act 1995 restricts any cultivation activity within a protected area (national parks and sanctuaries), while the Land Act 2007 allows herders to improve quality of the rangelands; (ii) initial investments for land preparation, sowing and operation costs (e.g. periodic weeding are required during the first season) were not covered. The benefits of improving pasture areas counteract the costs when the 
government aims to promote yak farming; and (iii) collaboration among herders, extensionists and park rangers was not organized and facilitated. Also, extensionists should have sufficient knowledge to provide technical inputs on developing improved pastures. For the future, overcoming these challenges is essential to make a success of pasture improvement. Stakeholders should be aligned and the division of roles between Parties must be clear. Improving pasture should be done with care, for example because of ecological consequences. Introduction of exotic species might give unforeseen consequences as has happened in Australia where exotic grasses have become invasive weeds (Driscoll et al., 2014; Norton et al., 2016). Such an example indicates that trade-offs should be prevented by studying a problem extensively taking all aspects into account before a new policy is implemented.

Another converging view on a problem and a solution among stakeholder groups was to encourage the non-yak farming families to keep a few heads of an improved cattle breed (high productive) instead of many heads of a local breed (low productive) to reduce forage competition. Most dairy farmers in Bhutan seem to prefer improved cattle breeds over the local breeds (Choden \& Tamang, 2018), so the government may adopt this strategy. However, keeping improved cattle breed by non-yak farming families also comes with wicked links (solutions to a problem may also have undesired side effects, Bos et al., 2009). Earlier studies demonstrated that the dairy developments (e.g. crossbreeding of local Siri cattle with Jersey) in the lowlands of Bhutan together with imported dairy products from India has affected the sales of yak products (Derville \& Bonnemaire, 2010; Phuntsho \& Dorji, 2016). Furthermore, the National Biodiversity Centre of Bhutan focuses on conserving and utilizing animal genetic resources sustainably because local cattle breeds are increasingly under threat. These local breeds should be conserved because they may contain genes to be adapted to the local conditions and are potentially required for future breeding work (Hoffmann, 2010). Again, potential trade-offs of choices in policy making should be considered carefully.

\subsection{Converging views on problems but diverging views on solutions}

Although there are multiple solutions proposed by the stakeholder groups to mitigate rural-urban migration (solution divergence), it is still uncertain whether these solutions will encourage young pastoralists to stay in yak farming. As for an immediate action plan, the governmental institutions should support yakbased communities in a way that their economic situation gets better (e.g. stimulate sales of yak products, diversify livelihoods). Tourism could potentially contribute to the economic situation of yak-based communities. So far, however, communities have hardly benefited because they are not involved in tourismrelated activities (Suntikul \& Dorji, 2016). Hence, policy makers should focus on building coalitions between the government, the tourism council and yak-based communities to ensure benefit-sharing of tourism. As an important step, policy makers could identify and categorize stakeholders based on the interest-influence matrix, which would assist policy makers to negotiate with different stakeholders if required in future (Heslinga et al., 2019).

From a conservationist perspective, Bhutan seems to succeed in protecting globally endangered animals such as for example, takin (Budorcas taxicolor), snow leopard, and Asiatic wild dog, but partly at the cost of livelihood of local communities. Similarly, loss of livestock to wild predators has increased over the years in the highlands of Nepal (Tiwari et al., 2020). One of many reasons was that park rangers did not allow herders to keep watch dogs, while they used to rear dogs in the past to look after the animals. Nonetheless, the increased number of yaks as perceived by yak herders probably displaced wild prey, in particular blue sheep (Pseudois nayaur), which might have led to increased human-wildlife conflicts. We have found no indication that the government intervenes to reduce yak losses to predators, though they pay a compensation fee for predation losses. In our opinion, herders should be more actively engaged in nature conservation by experiencing benefits. That can potentially be realized by introducing a conservation fee instead of a compensation fee, but also education and a (paid) role in conservation can be an incentive to converge solutions to problems. Such conservation performance schemes have been successfully applied in conserving endangered animals in Nepal (Dickman et al., 2011) and Sweden (Zabel \& Holm-Müller, 2008). Although a conservation performance scheme requires extensive surveys to record the number of endangered animals in a locality, the forestry department regularly studies distributions and population sizes of, for example, tigers (NCD, 2019) and snow leopards (DoFPS, 2016) using camera traps. This information could be used as a 
basis for compensating the communities sharing habitats with these endangered species. In this way the local community will be engaged in protecting endangered wildlife and this would be a 'win-win' situation for both herders and conservationists.

The issue of reducing or removing stray dogs from yak farming regions as a means to reduce yak mortality, interferes with individual and/or community sentiments. Herders found themselves in a dilemma whether to eliminate stray dogs or face the consequence of social pressure from the community for eliminating these animals. Rather, they would rely on the governmental bodies to set regulations or to remove these dogs somehow. In order to get to a generalized solution, the governmental institutions and NGOs should plan education programmes and management targeting different stakeholders (Wierzbowska et al., 2016) using several strategies such as: (i) encourage and reinforce safe disposal of wastes, to prevent that stray dogs are attracted; (ii) include instructions in tourists' guidelines (e.g. not throwing away their garbage but take it away for proper disposal); (iii) encourage dog owners to register their dogs and disallow pets to roam freely, and (iv) encourage sterilization if pets are not used for breeding (Kahn et al., 2008).

\subsection{Diverging views on problems and solutions}

There are trade-offs between conservation of natural resources and the traditional method of rejuvenating the rangelands. Most yak farming villages in Bhutan are within protected areas. Conservation of natural resources in these areas is the highest priority for the forest policy makers. The rangeland size has receded due to shrub proliferation as a result of enactment of the Forest Act 1995. As a consequence of rangeland degradation due to shrub proliferation, livestock production is affected due to low forage availability, plant richness is reduced (Pornaro et al., 2017), litter decomposition rate in rangeland is impaired (Brigham et al., 2018), and grassland ecosystems are disturbed (Archer et al., 2017; Koch et al., 2015; Myers-Smith \& Hik, 2018; Nautiyal \& Kaechele, 2007). It may also be argued that shrub proliferation in rangelands would allow for other species to establish, for instance the avian diversity in the Italian Alps has increased with increased shrub proliferation. However, most of these invading bird species are common and grassland bird species are threatened with extinction (Laiolo et al., 2004). Another benefit of shrub encroachment is that woody plants provide fuel woods, materials to construct fences and corrals (Reed et al., 2015), and increase carbon sequestration (Archer et al., 2017; Li et al., 2018). These facts overshadow the revising of the Forest Act. A collaborative learning process is recommended because any socio-technical transformation requires involvement of both academic and non-academic stakeholders (Restrepo et al., 2018). In the context of shrubs around rangelands to maintain rangeland conditions, governmental institutions need to organize multi-stakeholder dialogue aiming to discuss and clarify problems among stakeholder groups (Hirsch Hadorn et al., 2006; Pohl \& Hirsch Hadorn, 2008; Wanzenböck et al., 2019). Next, empirical evidence should be collected to understand synergies and trade-offs around burning rangelands, such as the impact on biodiversity. A prescribed burning in areas encroached by shrubs should be experimented (theory to practice) (van den Daele \& Krohn, 1998), involving all stakeholders to ensure transparency (Lindfors, 2020). Moreover, the experimentation should follow a recursive model because solutions may have unexpected side effects and this also adds knowledge to the process of innovations (Pohl \& Hirsch Hadorn, 2008). Subsequently, the captured information should be disseminated to relevant organizations. This implies that policy makers may need to design a clear objective, which includes the roles and contribution of each stakeholder, for effective implementation of the regulations through collaboration (Boaz et al., 2018; de Bruijn \& Heuvelhof, 2002).

The Bhutanese government aims to promote sustainable utilization of rangelands by redistributing rangelands to yak herders and livestock farmers because of absent owners (elite societies, monk bodies) (Phuntsho \& Dorji, 2016). The Land Act 2007 of Bhutan states that rangelands are nationalized and leased to yak herders and livestock farmers from 2017 onwards. However, because of poor explanation of the new act (Namgay et al., 2017) and a lack of coherence in the implementation strategy (Tenzing et al., 2017) confusion has arisen among different rangeland users. Consequently, the enactment of the law has led to conflicts between different rangeland users (Namgay et al., 2017; Phuntsho \& Dorji, 2016; Tenzing et al., 2017) as this act affects the existing agreed norms and rules of communities on the management of rangelands. Moreover, the Land Act 2007 of Bhutan was drafted by a team of civil servants from different 
governmental institutions, while transhumance communities were rarely involved in the process (Namgay et al., 2017). There is also supporting evidence regarding increased conflicts among pastoral communities due to disruption of the community collective rangeland management practice after nationalization of rangeland in Nepal (Dong et al., 2016) and disappearance of pastoral culture and an effect on pastoralists' livelihoods after implementation of the Rangeland Household Contract Policy in China (Gongbuzeren et al., 2015). This implies that relevant stakeholders should have been involved throughout the policymaking process. When this does not happen pastoralists may leave their traditional way of living and look for other livelihood (Kreutzmann, 2013). This happened, for example, in China where the government applied a top-down policy by forcing pastoralists into urbanization (e.g. pastoralists settle in towns) and modern farming (e.g. fencing rangelands, rangeland conversion into agricultural fields and applying pasture management, centralized livestock breeding).

\section{Policy implication and conclusions}

This research describes experienced threats to yak farming by different stakeholders and provides insight into problems and solutions from the perspective of different stakeholders. Herders consider forage availability and yak mortality as the main threats to yak farming, while government officials perceive labour availability (park rangers, livestock officials, forest officials) and rural-urban migration (extensionists, park rangers) as the main threat. In addition, livestock officials perceive forage availability also as a threat to yak farming. The triggers that we have identified from our analysis (e.g. yak product packaging design and develop improved pasture) may be prioritized for implementation to encourage yak herders to stay active in yak farming. It will also be valuable, however, to further investigate to what extent these triggers help to overcome challenges and barriers to yak farming. We acknowledge that even if the problems and solutions for approaching a problem converge among stakeholder groups, it does not necessarily mean that it is the best solution from a sustainability perspective. Several diverging views on the problems and solutions among different stakeholder groups indicate that there are possibly several challenges and barriers to sustain yak farming. There is a need for a multi-stakeholder dialogue aiming to discuss problems and solutions together. This should take away misleading and disputed claims, and provide understanding about the approach of yak-based communities to cope with risks and uncertainty around transhumance systems. This will also ensure that any future policy intervention to promote and facilitate sustainable yak farming is aligned with stakeholders' requirements. It is hoped that with strong collaboration and appropriate policy and legislation, this would reduce or remove challenges and barriers, which simultaneously give opportunities to yak herders and their children to stay in yak farming in future.

\section{Disclosure statement}

No potential conflict of interest was reported by the author(s).

\section{Funding}

This work was supported by Nuffic.

\section{Notes on contributors}

Nedup Dorji has been working as the lecturer at the College of Natural Resources, Royal University of Bhutan. He holds a PhD from the Wageningen University, The Netherlands. Prof.

Dr. Marjolein Derks is a postdoc in the Farm Technology Group Wageningen University, The Netherlands working on the design. In 2014, she started a postdoc in France and Sweden on modeling fertility in dairy cows using progesterone profiles.

Dr. Peter W.G. Groot Koerkamp has been working as a Professor at Farm Technology Group, Wageningen University, The Netherlands. His area of expertise includes Agricultural systems, Agricultural engineering, Animal production systems, Animal welfare, Agroecosystems, Sustainability, and Environmental technology.

Dr. Eddie Bokkers has been working as the Associate Professor at Animal Production Systems, Wageningen University, The Netherlands. His area of expertise includes animal production systems, animal welfare, sustainability, and animal husbandry.

\section{ORCID}

Nedup Dorji (D) http://orcid.org/0000-0002-5653-9748

\section{References}

Archer, S. R., Andersen, E. M., Predick, K. I., Schwinning, S., Steidl, R. J., \& Woods, S. R. (2017). Woody plant encroachment: Causes and consequences. In D. D. Briske (Ed.), Rangeland systems: Processes, management and challenges (pp. 25-84). Springer International Publishing. 
Boaz, A., Hanney, S., Borst, R., O'Shea, A., \& Kok, M. (2018). How to engage stakeholders in research: Design principles to support improvement. Health Research Policy and Systems, 16(1), 60. https://doi.org/10.1186/s12961-018-0337-6

Bos, A. P., Groot Koerkamp, P. W. G., Gosselink, J. M. J., \& Bokma, S. (2009). Reflexive interactive design and its application in a project on sustainable dairy husbandry systems. Outlook on Agriculture, 38(2), 137-145. https://doi.org/10 $.5367 / 000000009788632386$

Brigham, L. M., Esch, E. H., Kopp, C. W., \& Cleland, E. E. (2018). Warming and shrub encroachment decrease decomposition in arid alpine and subalpine ecosystems. Arctic, Antarctic, and Alpine Research, 50(1), e1494941. https://doi.org/10. 1080/15230430.2018.1494941

Bryson, J. M. (2004). What to do when stakeholders matter. Public Management Review, 6(1), 21-53. https://doi.org/10. 1080/14719030410001675722

Choden, D., \& Tamang, N. (2018). Breed preference and breeding practices of dairy farmers in Bhutan. Bhutan Journal of Animal Science, 2(1), 49-52.

de Bruijn, H., \& Heuvelhof, E. T. (2002). Policy analysis and decision making in a network: How to improve the quality of analysis and the impact on decision making. Impact Assessment and Project Appraisal, 20(4), 232-242. https://doi. org/10.3152/147154602781766627

Derville, M., \& Bonnemaire, J. (2010). Marginalisation of yak herders in Bhutan: Can public policy generate new stabilities that can support the transformation of their skills and organisations? Innovation and Sustainable Development in Agriculture and Food. ISDA 2010, Montpellier, France, 28 June-1 July 2010. (p. 10). Available from https://hal. archives-ouvertes.fr/hal-00522045/document.

Dickman, A. J., Macdonald, E. A., \& Macdonald, D. W. (2011). A review of financial instruments to pay for predator conservation and encourage human-carnivore coexistence. Proceedings of the National Academy of Sciences, 108(34), 13937-13944. https://doi.org/10.1073/pnas.1012972108

DoFPS. (2016). National snow leopard survey of Bhutan 20142016 (phase ii): Camera trap survey for population estimation. In E. DoFPS (Ed.), (p. 86). Ministry of Agriculture and Forests.

DoL. (2018). Livestock statistics 2018. In D. O. Livesotck (Ed.), (p. 342). Ministry of Agriculture and Forests.

Dong, S., Yi, S. L., \& Yan, Z. L. (2016). Maintaining the humannatural systems of pastoralism in the Himalayas of south Asia and China. In S. Dong, K.-A. S. Kassam, J. F. Tourrand, \& R. B. Boone (Eds.), Building resilience of human-natural systems of pastoralism in the developing world: Interdisciplinary perspectives (pp. 93-135). Springer International Publishing.

Dorji, N., Derks, M., Dorji, P., Groot Koerkamp, P. W. G., \& Bokkers, E. A. M. (2020). Herders' and livestock professionals' experiences on past and future developments in yak farming in Bhutan. Animal Production Science, 60(17), 2004-2020. https://doi.org/10.1071/AN1909

Driscoll, D. A., Catford, J. A., Barney, J. N., Hulme, P. E., Inderjit, T., Martin, T. G., Pauchard, A., Pyšek, P., Richardson, D. M., Riley, S., \& Visser, V. (2014). New pasture plants intensify invasive species risk. Proceedings of the National Academy of Sciences of the United States of America, 111(46), 16622-16627. https://doi.org/10.1073/pnas.1409347111
Gongbuzeren, Yanbo, L., \& Wenjun, L. (2015). China's rangeland management policy debates: What have we learned? Rangeland Ecology and Management, 68(4), 305-314. https://doi.org/10.1016/j.rama.2015.05.007

Gyan, C., \& Ampomah, A. O. (2016). Effects of stakeholder conflicts on community development projects in kenyase. SAGE Open, 6(1), 2158244016635254. https://doi.org/10. $1177 / 2158244016635254$

Haynes, M. A., \& Yang, Y. (2012). Adapting to change: Transitions in traditional rangeland management of Tibetan yak herders in northwest Yunnan. Environment, Development and Sustainability, 15(4), 1065-1077. https://doi.org/10.1007/ s10668-012-9426-9

Heslinga, J., Groote, P., \& Vanclay, F. (2019). Strengthening governance processes to improve benefit-sharing from tourism in protected areas by using stakeholder analysis. Journal of Sustainable Tourism, 27(6), 773-787. https://doi.org/10.1080/ 09669582.2017.1408635

Hirsch Hadorn, G., Bradley, D., Pohl, C., Rist, S., \& Wiesmann, U. (2006). Implications of transdisciplinarity for sustainability research. Ecological Economics, 60(1), 119-128. https://doi. org/10.1016/j.ecolecon.2005.12.002

Hoffmann, I. (2010). Climate change and the characterization, breeding and conservation of animal genetic resources. Animal Genetics, 41(s1), 32-46. https://doi.org/10.1111/j. 1365-2052.2010.02043.x

Kahn, S., Stuardo, L., \& Rahman, S. A. (2008). Oie guidelines on dog population control. Developments in Biologicals, 131, 511-516.

Koch, B., Edwards, P. J., Blanckenhorn, W. U., Walter, T., \& Hofer, G. (2015). Shrub encroachment affects the diversity of plants, butterflies, and grasshoppers on two Swiss subalpine pastures. Arctic, Antarctic, and Alpine Research, 47(2), 345-357. https://doi.org/10.1657/AAAR0013-093

Kreutzmann, H. (2013). The tragedy of responsibility in high Asia: Modernizing traditional pastoral practices and preserving modernist worldviews. Pastoralism: Research, Policy and Practice, 3(1), 7. https://doi.org/10.1186/2041-7136-3-7

Krishnan, G., Paul, V., Hanah, S. S., Bam, J., \& Das, P. J. (2016). Effects of climate change on yak production at high altitude. Indian Journal of Animal Sciences, 86(6), 621-626. Available from https://krishi.icar.gov.in/jspui/bitstream/123456789/ 5054/1/Dr.\%20G.\%20Krishnan-2016-Effects\%20of\% 20climate\%20change\%20on\%20yak\%20production\%20at\% 20high\%20altitude.pdf.

Krueger, R. A. (2002). Designing and conducting focus group interviews. Professor and Evaluation Leader, Univeristy of Minnesota, 1954 Buford Ave. St Paul. MN 55108. Available from https://www.eiu.edu/ihec/Krueger-FocusGrouplnterview s.pdf.

Krueger, R. A., \& Casey, M. A. (2000). Focus groups: A practical guide for applied research (4th ed). Sage Publications Inc.

Laiolo, P., Dondero, F., Ciliento, E., \& Rolando, A. (2004). Consequences of pastoral abandonment for the structure and diversity of the alpine avifauna. Journal of Applied Ecology, 41(2), 294-304. https://doi.org/10.1111/j.0021-8901. 2004.00893.x

Larsen, H. O., \& Smith, P. D. (2004). Stakeholder perspectives on commercial medicinal plant collection in Nepal. Mountain Research and Development, 24(2), 141-148. https://doi.org/ 10.1659/0276-4741(2004)024[0141:SPOCMP]2.0.CO;2 
Li, Q., Jia, Z., Feng, L., He, L., \& Yang, K. (2018). Dynamics of biomass and carbon sequestration across a chronosequence of caragana intermedia plantations on alpine sandy land. Scientific Reports, 8(1), 12432. https://doi.org/10.1038/ s41598-018-30595-3

Lindfors, A. (2020). Sustainability solutions: Lessons on assessment and facilitation. p. 36. Linköping University Electronic Press. https://doi.org/10.3384/lic.diva-164967

Loorbach, D. (2010). Transition management for sustainable development: A prescriptive, complexity-based governance framework. Governance, 23(1), 161-183. https://doi.org/10. 1111/j.1468-0491.2009.01471.x

Maheshwari, A., \& Sathyakumar, S. (2019). Snow leopard stewardship in mitigating human-wildlife conflict in Hemis National Park, Ladakh, India. Human Dimensions of Wildlife, 24(4), 395-399. https://doi.org/10.1080/10871209.2019. 1610815

MoAF. (2019). Twelfth Five Year Plan, 2018-2023. Ministry of Agriculture and Forests, Royal Government of Bhutan (Ed.). Policy and Planning Division. (pp: 169).

Moura, H. M., \& Teixeira, J. C. (2010). Managing stakeholders conflicts. In E. Chinyio \& P. Olomolaiye (Eds.), Construction stakeholder management (pp. 286-316). Wiley-Blackwell.

Myers-Smith, I. H., \& Hik, D. S. (2018). Climate warming as a driver of tundra shrubline advance. Journal of Ecology, 106(2), 547560. https://doi.org/10.1111/1365-2745.12817

Namgay, K., Millar, J. E., \& Black, R. S. (2017). Dynamics of grazing rights and their impact on mobile cattle herders in Bhutan. The Rangeland Journal, 39(1), 97-104. https://doi.org/10. 1071/RJ16052

Nautiyal, S., \& Kaechele, H. (2007). Adverse impacts of pasture abandonment in himalayan protected areas: Testing the efficiency of a natural resource management plan (nrmp). Environmental Impact Assessment Review, 27(2), 109-125. https://doi.org/10.1016/j.eiar.2006.10.003

NCD. (2019). Distribution and habitat use of tigers in Bhutan. DoFPS. Nature Conservation Division, Ministry of Agriculture and Forests (Ed.) (pp: 44). Thimphu.

Norton, M. R., Malinowski, D. P., \& Volaire, F. (2016). Plant drought survival under climate change and strategies to improve perennial grasses. Agronomy for Sustainable Development, 36(2), 29. https://doi.org/10.1007/s13593-0160362-1

Ochieng, N. T., Wilson, K., Derrick, C. J., \& Mukherjee, N. (2018). The use of focus group discussion methodology: Insights from two decades of application in conservation. Methods in Ecology and Evolution, 9(1), 20-32. https://doi.org/10. 1111/2041-210X.12860

Onwuegbuzie, A. J., Dickinson, W. B., Leech, N. L., \& Zoran, A. G. (2009). A qualitative framework for collecting and analyzing data in focus group research. International Journal of Qualitative Methods, 8(3), 1-21. https://doi.org/10.1177/ 160940690900800301

Phuntsho, K., \& Dorji, T. (2016). Yak herding in Bhutan: Policy and practice. In N. Wu, S. Yi, S. Joshi, \& N. Bisht (Eds.), Transboundary challenges and opportunities for yak raising in a changing Hindu Kush Himalayan region (pp. 147-163). International Centre for Integrated Mountain Development.

Pohl, C., \& Hirsch Hadorn, G. (2008). Methodological challenges of transdisciplinary research. Natures Sciences Sociétés, 16(2), 111-121. https://doi.org/10.1051/nss:2008035
Pornaro, C., Schneider, M. K., Leinauer, B., \& Macolino, S. (2017). Above- and belowground patterns in a subalpine grasslandshrub mosaic. Plant Biosystems - An International Journal Dealing with all Aspects of Plant Biology, 151(3), 493-503. https://doi.org/10.1080/11263504.2016.1187679

Reed, M. S., Stringer, L. C., Dougill, A. J., Perkins, J. S., Atlhopheng, J. R., Mulale, K., \& Favretto, N. (2015). Reorienting land degradation towards sustainable land management: Linking sustainable livelihoods with ecosystem services in rangeland systems. Journal of Environmental Management, 151, 472485. https://doi.org/10.1016/j.jenvman.2014.11.010

Restrepo, M. J., Lelea, M. A., \& Kaufmann, B. A. (2018). Evaluating knowledge integration and co-production in a 2-year collaborative learning process with smallholder dairy farmer groups. Sustainability Science, 13(5), 1265-1286. https://doi. org/10.1007/s11625-018-0553-6

Rosso, M., Bottero, M., Pomarico, S., La Ferlita, S., \& Comino, E. (2014). Integrating multicriteria evaluation and stakeholders analysis for assessing hydropower projects. Energy Policy, 67, 870-881. https://doi.org/10.1016/j.enpol.2013.12.007

Schmeer, K. (1999). Stakeholder analysis guidelines (pp: 48). Partnerships for Health Reform, Abt Associates Inc.

Shirasaka, K., Watanabe, T., Song, F., Liu, J., \& Miyahara, I. (2013). Transhumance in the Kyrgyz Pamir. Central Asia. Geographical Studies, 88(2), 82-101. https://doi.org/10.7886/hgs.88.80

Suntikul, W., \& Dorji, U. (2016). Tourism development: The challenges of achieving sustainable livelihoods in Bhutan's remote reaches. International Journal of Tourism Research, 18(5), 447-457. https://doi.org/10.1002/jtr.2062

Tenzing, K., Millar, J., \& Black, R. (2017). Changes in property rights and management of high-elevation rangelands in Bhutan: Implications for sustainable development of herder communities. Mountain Research and Development, 37(3), 353-366. https://doi.org/10.1659/MRD-JOURNAL-D-1700016.1

Tiwari, K. R., Sitaula, B. K., Bajracharya, R. M., Raut, N., Bhusal, P., \& Sengel, M. (2020). Vulnerability of pastoralism: A case study from the high mountains of Nepal. Sustainability, 12(7), 2737. https://doi.org/10.3390/su12072737

van den Daele, W., \& Krohn, W. (1998). Experimental implementation as a linking mechanism in the process of innovation. Research Policy, 27(8), 853-868. https://doi.org/10.1016/ S0048-7333(98)00095-X

Vannelli, K., Hampton, M. P., Tsewang, N., \& Black, S. A. (2019). Community participation in ecotourism and its effect on local perceptions of snow leopard (Panthera uncia) conservation. Human Dimensions of Wildlife, 24(2), 180-193. https:// doi.org/10.1080/10871209.2019.1563929

Vogel, C., Mathé, S., Geitzenauer, M., Ndah, H. T., Sieber, S., Bonatti, M., \& Lana, M. (2020). Stakeholders' perceptions on sustainability transition pathways of the cocoa value chain towards improved livelihood of small-scale farming households in Cameroon. International Journal of Agricultural Sustainability, 18(1), 55-69. https://doi.org/10.1080/ 14735903.2019.1696156

Wangchuk, K., \& Wangdi, J. (2015). Mountain pastoralism in transition: Consequences of legalizing cordyceps collection on yak farming practices in Bhutan. Pastoralism, 5(4), p. 10. https://doi.org/10.1186/s13570-015-0025-x

Wangchuk, K., \& Wangdi, J. (2018). Signs of climate warming through the eyes of yak herders in northern Bhutan. 
Mountain Research and Development, 38(1), 45-52. https:// doi.org/10.1659/MRD-JOURNAL-D-17-00094.1

Wangdi, J. (2016). The future of yak farming in Bhutan: Policy measures government should adopt. The Rangeland Journal, 38(4), 367-371. https://doi.org/10.1071/ RJ15111

Wanzenböck, I., Wesseling, J., Frenken, K., Hekkert, M., \& Weber, M. (2019). A framework for mission-oriented innovation policy: Alternative pathways through the problem-solution space. Science and Public Policy, 47(4), 474-489. https://doi. org/10.1093/scipol/scaa027
Wiener, G., Jianlin, H., \& Ruijun, L. (2003). The Yak RAP publication (p. 81). uuuu.

Wierzbowska, I. A., Hędrzak, M., Popczyk, B., Okarma, H., \& Crooks, K. R. (2016). Predation of wildlife by free-ranging domestic dogs in Polish hunting grounds and potential competition with the grey wolf. Biological Conservation, 201, 1-9. https://doi.org/10.1016/j.biocon.2016.06.016

Zabel, A., \& Holm-Müller, K. (2008). Conservation performance payments for carnivore conservation in Sweden. Conservation Biology, 22(2), 247-251. https://doi.org/10.1111/ j.1523-1739.2008.00898.x 